HELMINTHOLOGIA, 56, 3: 196 - 201, 2019

\title{
Determination of Echinococcus granulosus genotypes in livestock slaughtered in Shush County, Southwest Iran using PCR-RFLP
}

\author{
S. FALLAHIZADEH ${ }^{1,3}$, R. ARJMAND ${ }^{1,2}$, A. JELOWDAR ${ }^{1,2, *}$, A. RAFIEI ${ }^{1,2}$, F. KAZEMI ${ }^{3}$ \\ ${ }^{1}$ Infectious and Tropical Diseases Research Center, Health Research Institute, Ahvaz Jundishapur University of Medical Sciences, \\ Ahvaz, Iran, *E-mail: jelowdar@gmail.com; ${ }^{2}$ Department of Parasitology, School of Medicine, Ahvaz Jundishapur University of Medical \\ Sciences, Ahvaz, Iran; ${ }^{3}$ Student Research Committee, Ahvaz Jundishapur University of Medical Sciences, Ahvaz, Iran
}

Article info

Received January 10, 2019

Accepted June 14, 2019

\section{Summary}

Echinococosis is a zoonotic disease caused by the larval stages of Echinococcus spp. that occurs in most parts of the world. Herein, we aimed to evaluate the genotypes of isolated hydatid cysts from slaughtered animals in Shush county, southwestern Iran. Totally, 96 hydatid cysts were collected, including 11 buffaloes, 13 cattle, 12 goat and 60 sheep. The PCR was done by a primer pair (BDI and 4s) to amplify ITS1 fragment. Four restriction endonucleases including Alul, Hpall, Rsal, and Taql were used for RFLP products and enzymatic reactions were electrophoresed. Finally, twenty PCR products were sent for sequencing and phylogenetic tree was drawn with MEGA6. Molecular identification of 96 hydatid cysts demonstrated a distinctive 1000 bp fragment in all samples from four animal hosts. RFLP analysis showed similar digestion patterns in all samples. Alul digestion yielded 800 bp and 200 bp fragments, Hpall digestion made 700 bp and 300 bp fragments and Rsal digestion entailed 655 and 345segments. Moreover, Taql rendered no digestion pattern on rDNA-ITS1 region. Additionally, E. granulosus sensu stricto (G1-3 complex) was the prevailing genotype in all livestock samples, according to PCR-RFLP and sequencing analyses.

Keywords: Echinococcus granulosus; genotypes; livestock; Shush County; PCR-RFLP

\section{Introduction}

As an ancient zoonotic parasitosis, cystic echinococcosis (CE) is still a landmark neglected tropical disease around the globe, rendered by Echinococcus granulosus ( $E$. granulosus) larval stage (Cardona \& Carmena, 2013; Ito \& Budke, 2017; Moro, P. \& Schantz, 2009). The endemicity of CE is appointed to various parts of the world, including South America, the Middle East, and Mediterranean zone, northeastern Africa as well as Australia (Ito \& Budke, 2017; Rojas et al., 2014). Iran is considered as an endemic area for $C E$ in the Middle East region, specifically owing to traditional animal husbandry and availability of abattoir wastes to dogs (Rokni, 2009). Based on slaughterhouse investigations, the animal prevalence rates in hyperendemic areas ranges from $20 \%$ to $95 \%$. Also, it is estimated that US\$ 3 billion is considered for case treatment and livestock losses (Who, 2017). Being a cyclozoonosis, the continuity of the $E$. granulosus life cycle is relied on the ecological interactions between domestic/wild canid populations (definitive hosts) and ungulates (intermediate hosts) in the natural environment. In this regard, there exist two ecological cycles of the hydatidosis: the domestic cycle frequently found in countries with sheep and cattle farming, and sylvatic cycle involving feral carnivores and wild herbivores (Carmena \& Cardona, 2014; Otero-Abad \& Torgerson, 2013). Although rare, aberrant human infections may occur via accidental ingestion of parasite eggs shed in dog feces in communities with poor sanitation practices (Rokni, 2009; Torgerson et al., 2002).

From phenotypic characters and gene sequences standpoint, $E$.

\footnotetext{
$\bar{*}$ - corresponding author
} 


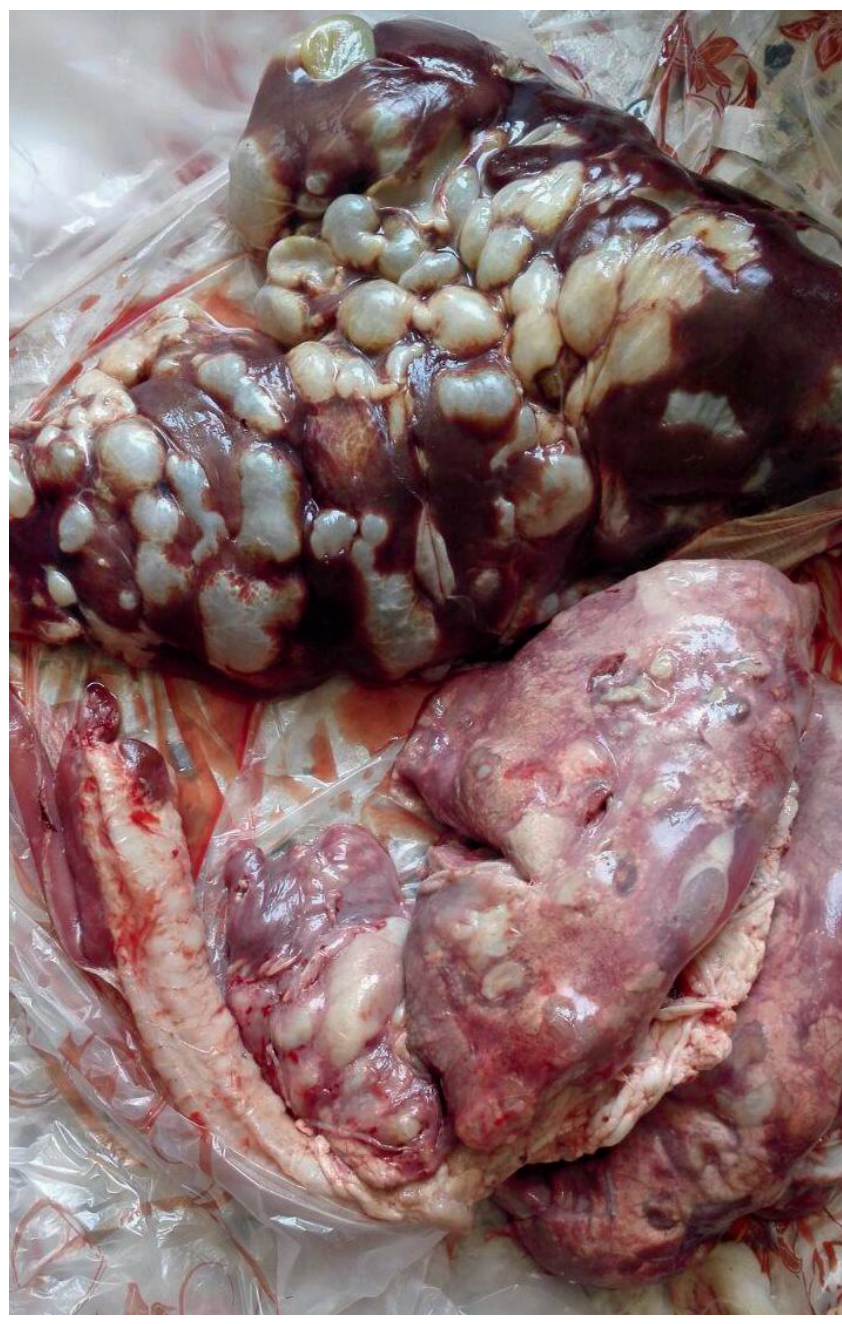

Fig. 1. Collected hydatid cyst samples from slaughtered livestock in Shush abattoir.

granulosus sensu lato is currently divided into genotypes $\mathrm{G} 1-\mathrm{G} 10$ of which $E$. granulosus sensu stricto ( $\mathrm{G} 1-3$ complex) are the most frequently implicated genotypes in human infections. E. felidis (the former 'lion strain'), E.equinus (the 'horse strain', G4), E. ortleppi (the'cattle strain', G5), E. canadensis and the latter species, as recognized here, shows the highest diversity and is composed of the 'camel strain', G6, the 'pig strain', G7,and two 'cervid strains', G8 and G10 (Kinkar et al., 2017; Moazeni-Bistgani et al., 2013). $\mathrm{G} 1$ is the most eminent and exclusive cause of human and animal infection, cycling between dogs and sheep in vast pastoral lands globally; however, phylogenetic evidence demonstrate that other animals such as goat, cattle, and camel, also, act as minor intermediate hosts for this genotype (Lymbery, 2017). So far, many molecular tests have been used to discern the genotypic characteristics of E. granulosus (Ito \& Budke, 2017). Polymerase chain reaction - restriction fragment length polymorphism (PCR-RFLP) is a verified molecular diagnostic for genotype detection, based on sequence-specific endonucleases (Bowles \& Mcmanus, 1993;
Dousti et al., 2013; Mcmanus, 2002). Alterations in the genetic variants of $E$. granulosus populations, their host diversity, and public health importance would emphasize the molecular discernment of E. granulosus genotypes (Craig et al., 2007; Moazeni-Bistgani , Taghipoor et al., 2013; Siles-Lucas \& Gottstein, 2001). Herein, we investigated the prevalence of $E$. granulosus genotypes in slaughtered livestock of Shush city, Khuzestan province, Southwest of Iran.

\section{Materials and Methods}

\section{Study area and sample collection}

Shush city is located in Khuzestan province, Southwest of Iran, have $3,577 \mathrm{~km}^{2}$ area and dry and hot weather, with air temperatures ranging +1 and $+53^{\circ} \mathrm{C}$. During March - November 2017, a total number of 96 hydatid cysts were collected from slaughtered livestock at Shush abattoir, including 11 buffaloes, 13 cattle, 12 goats and 60 sheep (Fig. 1). Protoscolices of $E$. granulosus were removed from hydatid cyst contents and prepared as previously described by Smyth et al. and Balbinotti et al. (Balbinotti et al., 2012; Smyth \& Davies, 1974) Briefly, the hydatid cysts were aspirated and examined microscopically for cyst fertility. Protoscoleces that aspirated from fertile cyst were rinsed multiple times with sterile $0.9 \%$ sodium chloride solution and maintained in $70 \%$ ethanol for molecular purposes.

\section{DNA extraction and PCR amplification}

At first, all stored samples were washed twice with PBS to remove ethanol. The DNA extraction procedure was accomplished using PrimePrep genomic DNA isolation kit from tissue (GeNet Bio, South Korea) based on the manufacturer's protocol and the genomic DNA was kept at $-20^{\circ} \mathrm{C}$ for PCR reaction. The concentration of each DNA sample was measured by NanoDrop (Thermo, USA) evaluation at A260. In each sample, an Internal Transcribed

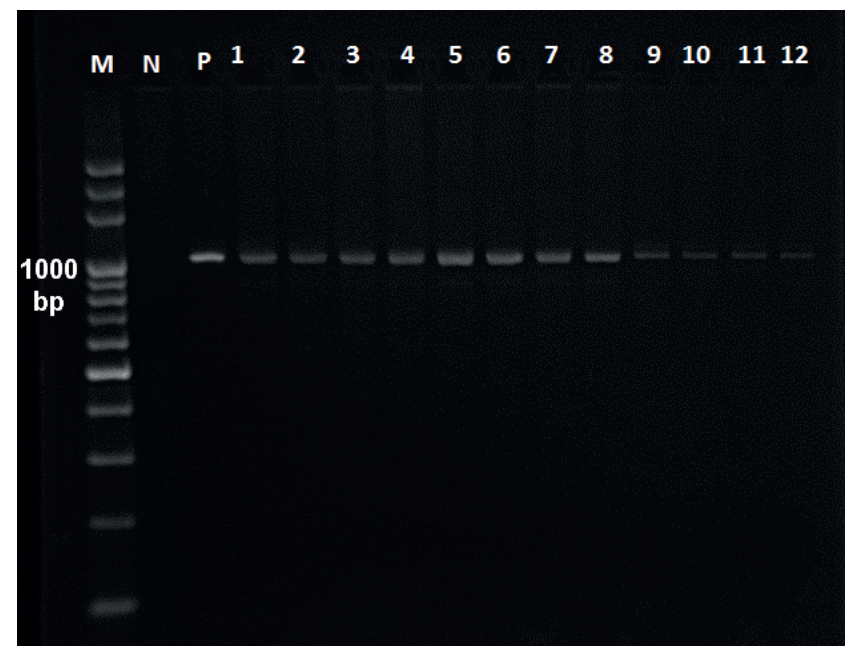

Fig. 2. Distinctive $1000 \mathrm{bp}$ amplified fragment for $E$. granulosus ITS1 in conventional PCR. 


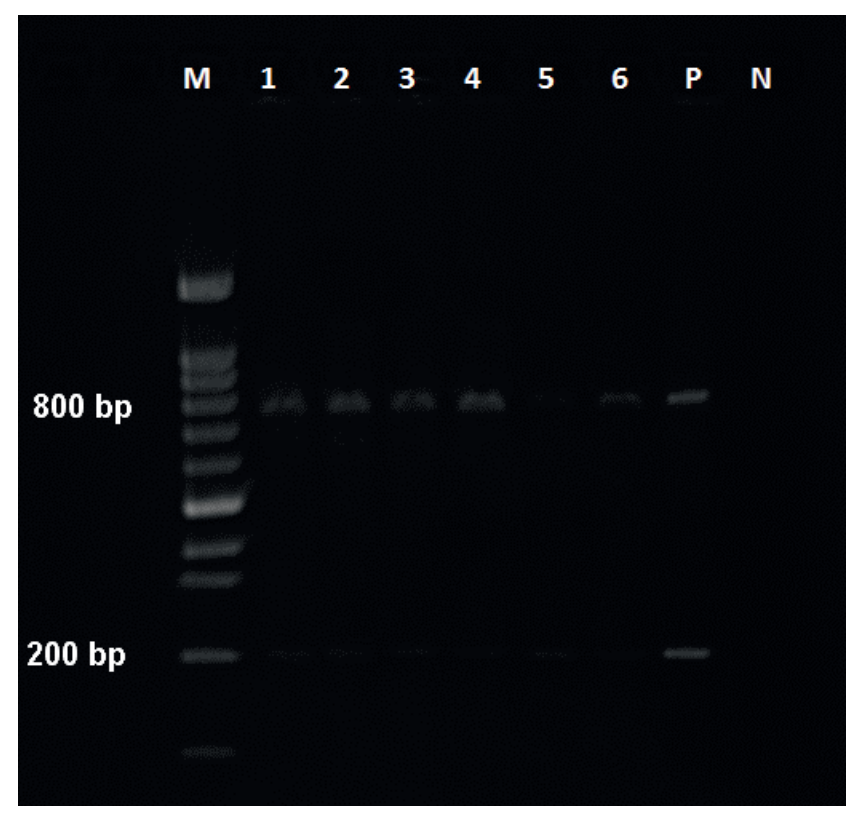

Fig. 3. Enzymatic digestion with Alul. Lanes 1,2: sheep; lanes 3,4: cattle; lane 5: buffalo; lane 6: goat; lanes 7 and 8: positive and negative controls, respectively.

Spacer 1 (ITS1) fragment was amplified by conventional PCR, using a specific primer pair:

BDI (5'-GTCCTAACAAGGTTTCCGTA-3') for the 18S region. 4S (5/-TCTAGCGTTCGAA(G/A)TGTCGATG-3) for the 5.8S region. A $25 \mu \mathrm{l} \mathrm{PCR} \mathrm{mixture} \mathrm{was} \mathrm{prepared} \mathrm{for} \mathrm{each} \mathrm{sample,} \mathrm{containing}$ $12.5 \mu$ l of Master Mix (Ampliqon, Denmark), $3 \mu$ of extracted DNA, ten pmol of each primer and $6.5 \mu \mathrm{l}$ of sterilized water. The following PCR program was carried out in an automated thermo cycler (FlexCycler, Analytik Jena, Germany): an initial denaturation step at $95^{\circ} \mathrm{C}$ for $5 \mathrm{~min}, 30$ cycles of denaturation at $94^{\circ} \mathrm{C}$ for $30 \mathrm{sec}$, annealing at $55^{\circ} \mathrm{C}$ for $45 \mathrm{sec}$, and extension at $72^{\circ} \mathrm{C}$ for $45 \mathrm{sec}$, followed by a final extension step at $72^{\circ} \mathrm{C}$ for $5 \mathrm{~min}$. Finally, the PCR products were separated by $1.5 \%$ agarose gel electrophoresis and displayed under ultraviolet (UV) illumination.

\section{Enzymatic digestion}

To perform PCR-RFLP, four specific restriction endonucleases, enclosing Alul (AG/CT), Hpall (C/CGG) (Jena Bioscience, Jena, Germany), Rsal (GT/AC) and Taql (T/CGA) (Thermo Scientific, Massachusetts, United States) were used. In case of digestion with Rsal and Taql, the procedure was done in $50 \mu$ reaction mixture, including $5 \mu$ of the universal buffer, one $\mu \mathrm{g}$ of pure DNA or PCR product, $10 \mathrm{U}$ of enzyme and PCR-grade water for the rest. The prepared mixtures were incubated in a thermocycler, being set to $37^{\circ} \mathrm{C}$ for Rsal and $65^{\circ} \mathrm{C}$ for Taql, both for 2 hours. Also the digestion mixture for Alul and Hpall included Tango buffer $(2 \mu \mathrm{l})$, PCR product $(10 \mu \mathrm{l})$, enzyme $(1-2 \mu \mathrm{l})$ and nuclease-free water $(18 \mu \mathrm{l})$, which incubated at $37^{\circ} \mathrm{C}$ for an hour. All digested products were visualized using $2 \%$ agarose gel electrophoresis and under UV condition.

\section{Sequencing and phylogenetic analysis}

Twenty PCR products were submitted to be sequenced by an ABI3730XL capillary machine (Macrogen Inc., South Korea) in two directions using forward and reverse primers. The sequencing results were interpreted and compared to other GenBank registered sequences using the BLAST tool (http://www.ncbi.nlm.nih.gov/ BLAST/). Multiple alignments was exerted by ClustalX and Bioedit software to align and compare obtained nucleotide sequences. Neighbor-joining approach using MEGA 6 bioinformatics software was used to create the phylogenetic tree.

\section{Ethical Approval and/or Informed Consent}

The study protocol No: IR.AJUMS.REC.1396.410 was approved by the Ethics Committee on Research in School of Medicine, Ahvaz Jundishapur University of Medical Sciences

\section{Results}

In total, 96 hydatid cyst isolates were collected from slaughtered domestic animals of Shush abattoir. Molecular identification of hydatid cysts by conventional PCR showed a distinctive 1000 base pair (bp) fragment in all samples from four animal hosts (Fig. 2). The PCR-RFLP analysis of ITS1 segment of $E$. granulosus cysts demonstrated similar digestion patterns in all samples. Alul digestion yielded 800 bp and 200 bp fragments (Fig. 3), Hpall digestion made 700 bp and 300 bp fragments (Fig. 4), and Rsal digestion entailed $655 \mathrm{bp}$ and $345 \mathrm{bp}$ segments (Fig. 5). Moreover, Taql rendered no digestion pattern on rDNA-ITS1 region (Fig. 6). Also, molecular sequencing disclosed that all 20 hydatid cysts were $E$. granulosus sensu stricto genotype and no other strains were discovered.

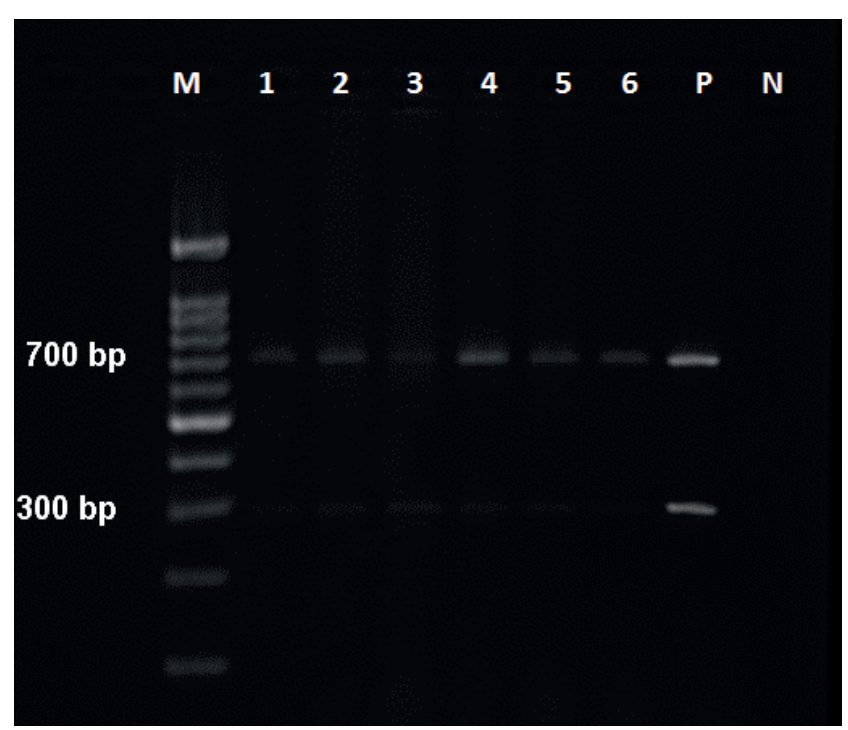

Fig. 4. Enzymatic digestion with Hpall. Lanes 1,2: sheep; lanes 3,4: cattle; lane 5: buffalo; lane 6: goat; lanes 7 and 8: positive and negative controls, respectively. 


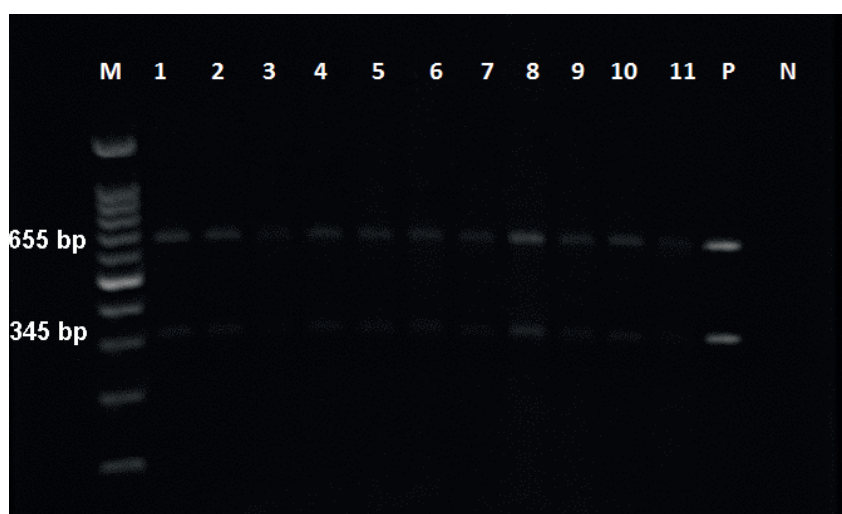

Fig. 5. Enzymatic digestion with Rsal. Lanes 1-4: sheep; lanes 5-7: cattle; lanes 8, 9: buffalo; lanes 10, 11: goat; lanes 12 and 13: positive and negative controls, respectively.

\section{Discussion}

Hydatidosis is a major public health issue in endemic countries such as Iran (Rokni, 2009). Determination of variations in E. granulosus genotypes is an interesting standpoint of hydatidosis research, to better understand ecological processes and life cycle patterns. The accurate taxonomy of $E$. granulosus isolates can be revealed by a wide array of molecular approaches (Carmena \& Cardona, 2014; Cucher et al., 2015; Mcmanus \& Bowles, 1996). The ITS segment of rDNA, particularly ITS1, has been proved to be an impressive genetic marker for Echinococcus genotyping studies (Fadakar et al., 2015; Siles-Lucas et al., 2017). Concerning Bowels et al., a 1000 bp band was observed in all 96 specimens by amplification of rDNA-ITS1 fragment, highlighting the E. granulosus identity (Bowles et al., 1995; Bowles \& Mcmanus, 1993). Additionally, E. granulosus sensu stricto was the prevailing

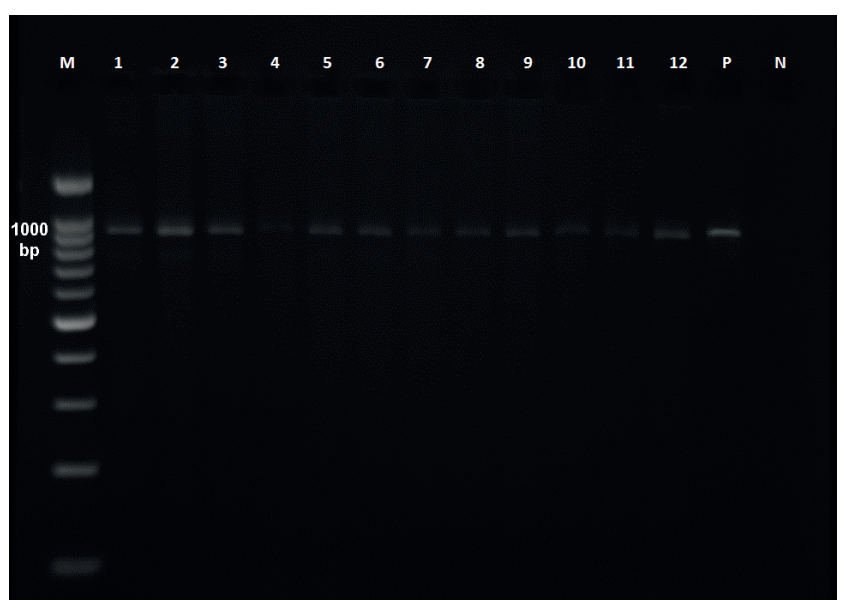

Fig. 6. Enzymatic digestion with Taql. Lanes 1-4: sheep; lanes 5-7: cattle; lanes 8, 9: buffalo; lanes 10, 11: goat; lanes 12 and 13: positive and negative controls, respectively. genotype in all livestock samples, according to PCR-RFLP and sequencing analyses. Reportedly, previous investigations across the country have demonstrated the sheep strain as the major detected genotype of CE in production animals (Ahmadi \& Dalimi, 2006; Harandi et al., 2002; Moghaddas et al., 2015; Pezeshki et al., 2013; Pour et al., 2011; Sharbatkhori et al., 2010; Sharbatkhori et al., 2016; Zhang et al., 1998). Khademvatan et al. reported G1 as the only cause of hydatid cyst in 329 examined livestock (sheep, cattle, and goat) of southwestern Iran, using PCR-RFLP with Alul, Mspl and Rsal restriction endonucleases (Khademvatan et al., 2013). Based on a genotyping study in Isfahan province, animal hydatid cysts from sheep, camel, cattle, and goat were characterized using PCR-RFLP with the same primers and enzymes as our study; it was demonstrated that the sheep strain is the most prevalent isolate among these animals (Shahnazi et al., 2011). In a neighbor province, hydatid isolates were gathered from sheep, goat, and cattle; likewise ours, the authors used Taql, Alul, Rsal and Hpall and showed G1 as the frequent strain (Parsa et al., 2011). In contrast with our study that used ITS1, Sharbatkhori et al. used cytochrome $C$ oxidase subunit 1 (cox1) and NADH dehydrogenase 1 (nad1) mitochondrial genes for sequencing and detected G1 (78.3 \%) in all animal hosts such as sheep, goat, cattle, camel and buffalo in Golestan province (Sharbatkhori , Tanzifi et al., 2016). Our results are compatible with these findings. Also, there exist convincing molecular proofs all over the globe suggesting $\mathrm{G} 1$ infection of sheep, cattle, goat, and buffalo, enclosing investigations in Iraq (Hammad et al., 2018), Pakistan (Latif et al., 2010), India (Singh et al., 2012), Argentina (Andresiuk et al., 2013), Ethiopia (Tigre et al., 2016) and Greece (Chaligiannis et al., 2015). The current investigation likewise several studies (Khademvatan , Yousefi et al., 2013; Moro, P. L. et al., 2009; Parsa , Haghpanah et al., 2011; Pour , Hosseini et al., 2011; Sharbatkhori , Tanzifi et al., 2016; Varcasia et al., 2006) have also isolated G1 from other animals rather than sheep, and goat, such as cattle/buffalo, suggesting the dominance of this genotype in these animals. Although, it is noticeable that $\mathrm{G} 1$ frequently renders infertile hydatid cysts in cattle (Hüttner \& Romig, 2009). This finding also emphasizes the interaction of different ecological cycles of CE and warrants further researches to disclose the epidemiology and transmission dynamics of hydatidosis in Iran.

Regarding our results, E. granulosus sensu stricto was the predominant genotype in slaughtered sheep, goat, cattle and buffalo of this area, southwestern Iran, similar to other parts of the country. This strain is supposed as the most known genotype of $E$. granulosus with potential serious sequela in humans. Obtained results from this study would shed light for local and nation-wide CE preventive measures, consisting of improved diagnostics and better therapeutics.

\section{Conflict of Interest Statement}

We declare that we have no conflict of interest. 


\section{Acknowledgments}

This article is based on the Master's Thesis, sponsored by the Infectious and Tropical Diseases Research Center, Health Research Institute, Ahvaz Jundishapur University of Medical Sciences. The authors would like to acknowledge the Deputy Research of Jundishapur University of Medical Sciences for their support.

\section{References}

Ahmadi, N., Dalimi, A. (2006): Characterization of Echinococcus granulosus isolates from human, sheep and camel in Iran. Infect. Genet. Evol., 6(2): 85 - 90. DOI: 10.1016/j.meegid.2005.01.005

Andresiuk, M., Gordo, F., Saarma, M., Elissondo, M., Taraborelli, A., Casalongue, C., Denegri, G., Saarma, U. (2013): Echinococcus granulosus genotype $\mathrm{G} 1$ dominated in cattle and sheep during 2003 - 2006 in Buenos Aires province, an endemic area for cystic echinococcosis in Argentina. Acta Trop., 127(2): 136 - 142. DOI: 10.1016/j.actatropica.2013.04.008

Balbinotti, H., Santos, G., Badaraco, J., Arend, A., Graichen, D., HAAG, K., ZAHA, A. (2012): Echinococcus ortleppi (G5) and Echinococcus granulosus sensu stricto (G1) loads in cattle from Southern Brazil. Vet. Parasitol., 188(3 - 4): 255 - 260. DOI: 10.1016/j. vetpar.2012.04.007

Bowles, J., BLAIR, D., Mcmanus, D.P. (1995): A molecular phylogeny of the genus Echinococcus. Parasitology, 110(3): 317 - 328. DOl: 10.1017/S0031182000080902

Bowles, J., Mcmanus, D.P. (1993): Rapid discrimination of Echinococcus species and strains using a polymerase chain reaction-based RFLP method. Mol. Biochem. Parasitol., 57(2): 231 - 239. DOI: 10.1016/0166-6851(93)90199-8

Cardona, G.A., Carmena, D. (2013): A review of the global prevalence, molecular epidemiology and economics of cystic echinococcosis in production animals. Vet. Parasitol., 192(1 - 3): 10 - 32. DOI: 10.1016/j.vetpar.2012.09.027

Carmena, D., Cardona, G.A. (2014): Echinococcosis in wild carnivorous species: epidemiology, genotypic diversity, and implications for veterinary public health. Vet. Parasitol., 202(3): 69 - 94. DOI: 10.1016/j.vetpar.2014.03.009

Chaligiannis, I., Malllard, S., Boubaker, G., Spiliotis, M., Saratsis, A., GotTSTEIn, B., SotIRAKI, S. (2015): Echinococcus granulosus infection dynamics in livestock of Greece. Acta Trop., 150: 64 - 70. DOI: 10.1016/j.actatropica.2015.06.021

Craig, P.S., Mcmanus, D.P., Lightowlers, M.W., Chabalgoity, J.A., Garcia, H.H., Gavidia, C.M., Gilman, R.H., Gonzalez, A.E., Lorca, M., NAQUIRA, C. (2007): Prevention and control of cystic echinococcosis. Lancet Infect. Dis., 7(6): 385 - 394. DOI: 10.1016/S14733099(07)70134-2

Cucher, M.A., Macchiaroli, N., Baldi, G., Camicia, F., Prada, L., Maldonado, L., Avila, H.G., Fox, A., Gutiérrez, A., Negro, P. (2015): Cystic echinococcosis in South America: systematic review of species and genotypes of Echinococcus granulosus sensu lato in hu- mans and natural domestic hosts. Trop. Med. Int. Health, (2):166 - 175. DOI: 10.1111/tmi.12647

Dousti, M., Abdi, J., BakhtiYarl, S., Mohebal, M., Mirhendi, S., RoKNI, M. (2013): Genotyping of hydatid cyst isolated from human and domestic animals in llam Province, Western Iran using PCRRFLP. Iran. J. Parasitol., 8(1): 47

Fadakar, B., Tabatabael, N., BorJI, H., Naghibl, A. (2015): Genotyping of Echinococcus granulosus from goats and sheep indicating G7 genotype in goats in the Northeast of Iran. Vet. Parasitol., 214(1): 204 - 207. DOI: 10.1016/j.vetpar.2015.09.029

Hammad, S.J., Cavallero, S., Milardi, G.L., Gabrielli, S., Al-Nasirl, F.S. (2018): Molecular genotyping of Echinococcus granulosus in the North of Iraq. Vet. Parasitol., 249: 82 - 87. DOI: 10.1016/j. vetpar.2017.11.010

Harandi, M.F., Hobbs, R., Adams, P., Mobedi, I., Morgan-Ryan, U., Thompson, R. (2002): Molecular and morphological characterization of Echinococcus granulosus of human and animal origin in Iran. Parasitology, 125(04): 367 - 373. DOI: 10.1017/ S0031182002002172

HütTner, M., Romig, T. (2009): Echinococcus species in African wildlife. Parasitology, 136(10): 1089 - 1095. DOI: 10.1017/ S0031182009990461

ITo, A., BudKE, C.M. (2017): The echinococcoses in Asia: The present situation. Acta Trop., 176(1): 11 - 21. DOI: 10.1016/j.actatropica.2017.07.013

Khademvatan, S., Yousefi, E., Rafiel, A., Rahdar, M., Saki, J. (2013): Molecular characterization of livestock and human isolates of Echinococcus granulosus from south-west Iran. J. Helminthol., 87(2): 240 - 244. DOI: 10.1017/S0022149X12000296

Kinkar, L., Laurimäe, T., Sharbatkhori, M., Mirhendi, H., Kia, E.B., Ponce-Gordo, F., Andresiuk, V., Simsek, S., LaVIIKaINen, A., IrShadulLAH, M. (2017): New mitogenome and nuclear evidence on the phylogeny and taxonomy of the highly zoonotic tapeworm Echinococcus granulosus sensu stricto. Infect. Genet. Evol., 52: 52 - 58. DOI: 10.1016/j.meegid.2017.04.023

Latif, A.A., Tanveer, A., Magbool, A., SiddiQI, N., Kyaw-Tanner, M., TRAUB, R. J. (2010): Morphological and molecular characterisation of Echinococcus granulosus in livestock and humans in Punjab, Pakistan. Vet. Parasitol., 170(1): 44 - 49. DOI: 10.1016/j.vetpar.2010.02.003

Lymbery, A. (2017). Phylogenetic pattern, evolutionary processes and species delimitation in the genus Echinococcus Adv. Parasitol., 95: $111-145$

McManus, D. (2002): The molecular epidemiology of Echinococcus granulosus and cystic hydatid disease. Trans. R. Soc. Trop. Hyg., 96: S151 - S157. DOI: 10.1016/S0035-9203(02)90068-4 McManus, D., Bowles, J. (1996): Molecular genetic approaches to parasite identification: their value in diagnostic parasitology and systematics. Int. J. Parasitol., 26(7): 687 - 704. DOI: 10.1016/0020-7519(96)82612-9

Moazenl-Bistganl, M., Taghipoor, S., Abolhasani, M., Hashemzadeh-Chaleshtori, M., Zarean, E., Yousofi Darani, H. (2013): Molec- 
ular characterization of the human and sheep hydatid cyst strains in Chaharmahal va Bakhtiari province of Iran using restriction fragment length plolymorphism (PCR RFLP). Cell Biol., 2(2)

Moghaddas, E., Boru, H., NaghiBl, A., Shayan, P., Razmi, G.R. (2015): Molecular genotyping of Echinococcus granulosus from dromedaries (Camelus dromedarius) in eastern Iran. J. Helminthol., 89(1): 100 - 104. DOI: 10.1017/S0022149X13000631

MoRo, P., Schantz, P.M. (2009): Echinococcosis: a review. Int. J. Infect. Dis., 13(2): 125 - 133. DOI: 10.1016/j.jijid.2008.03.037

Moro, P.L., Nakao, M., Ito, A., Schantz, P.M., Cavero, C., CabreRA, L. (2009): Molecular identification of Echinococcus isolates from Peru. Parasitol. Int., 58(2): 184 - 186. DOI: 10.1016/j. parint.2009.01.005

Otero-Abad, B., Torgerson, P. R. (2013): A systematic review of the epidemiology of echinococcosis in domestic and wild animals. PLoS Negl. Trop. Dis., 7(6): e2249. DOI: 10.1371/journal. pntd.0002249

Parsa, F., Haghpanah, B., Pestechian, N., Salehi, M. (2011): Molecular epidemiology of Echinococcus granulosus strains in domestic herbivores of Lorestan, Iran. Jundishapur J..Microbiol., 4(2): 123 $-130$

Pezeshil, A., Akhlaghi, L., Sharbatkhori, M., Razmuou, E., Oormazdi, H., Mohebali, M., Meamar, A. (2013): Genotyping of Echinococcus granulosus from domestic animals and humans from Ardabil Province, northwest Iran. J. Helminthol., 87(4): 387 - 391. DOI: 10.1017/S0022149X1200051X

Pour, A.A., Hosseinl, S. H., Shayan, P. (2011): Comparative genotyping of Echinococcus granulosus infecting buffalo in Iran using cox1 gene. Parasitol. Res., 108(5): 1229 - 1234. DOI: $10.1007 /$ s00436-010-2170-x

ROJAS, C.A.A., RomIG, T., LIGHTOWLERS, M.W. (2014): Echinococcus granulosus sensu lato genotypes infecting humans - review of current knowledge. Int. J. Parasitol., 44(1): 9 - 18. DOI: 10.1016/j. ijpara.2013.08.008

RoKNI, M. (2009): Echinococcosis/hydatidosis in Iran. Iran. J. Parasitol., 4(2): 1 - 16

Shahnazl, M., Hejazl, H., Salehi, M., Andalib, A. R. (2011): Molecular characterization of human and animal Echinococcus granulosus isolates in Isfahan, Iran. Acta Trop., 117(1): 47 - 50. DOI: 10.1016/j.actatropica.2010.09.002

Sharbatkhori, M., Mirhendi, H., Harand, M.F., Rezaeian, M., Moheball, M., Eshraghian, M., Rahimi, H., KIA, E.B. (2010): Echinococcus granulosus genotypes in livestock of Iran indicating high frequency of G1 genotype in camels. Exp. Parasitol., 124(4): 373 - 379. DOI: 10.1016/j.exppara.2009.11.020

Sharbatkhori, M., Tanzifi, A., Rostami, S., Rostami, M., Harandi, M.F. (2016): Echinococcus granulosus sensu lato genotypes in domestic livestock and humans in Golestan province, Iran. Rev. Inst. Med. Trop. Sao Paulo, 58: 38. DOI: 10.1590/S1678-9946201658038

Siles-Lucas, M., Casulli, A., Conraths, F., Müller, N. (2017). Laboratory diagnosis of Echinococcus spp. in human patients and infected animals. Adv. Parasitol., 96: 159 - 257. DOI: 10.1016/ bs.apar.2016.09.003

Siles-Lucas, M., GotTstein, B. (2001): Molecular tools for the diagnosis of cystic and alveolar echinococcosis. Trop. Med. Int. Health, 6(6): 463 - 475. DOI: 10.1046/j.1365-3156.2001.00732.x

Singh, B.B., Sharma, J.K., Ghatak, S., Sharma, R., Bal, M.S., Tul, A., GILL, J.P.S. (2012): Molecular epidemiology of Echinococcosis from food producing animals in north India. Vet. Parasitol., 186(3 4): 503 - 506. DOI: 10.1016/j.vetpar.2011.11.064

SMYTH, J., Davies, Z. (1974): In vitro culture of the strobilar stage of Echinococcus granulosus (sheep strain): a review of basic problems and results. Int. J. Parasitol., 4(6): 631 - 644. DOI: 10.1016/0020-7519(74)90028-9

Tigre, W., Deresa, B., Halle, A., Gabriël, S., Victor, B., Van Pelt, J., Devleesschauwer, B., Vercruysse, J., Dorny, P. (2016): Molecular characterization of Echinococcus granulosus sl cysts from cattle, camels, goats and pigs in Ethiopia. Vet. Parasitol., 215: 17 - 21. DOI: 10.1016/j.vetpar.2015.10.022

Torgerson, P., Shaikenov, B., Baitursinov, K., Abdybekova, A. (2002): The emerging epidemic of echinococcosis in Kazakhstan. Trans. R. Soc. Trop. Hyg., 96(2): 124 - 128. DOI: 10.1016/S00359203(02)90276-2

Varcasia, A., Canu, S., Lightowlers, M.W., Scala, A., Garippa, G. (2006): Molecular characterization of Echinococcus granulosus strains in Sardinia. Parasitol. Res., 98(3): 273 - 277. DOI: 10.1007/ s00436-005-0059-x

WHO. (2017): Meeting of the WHO Informal Working Group on Echinococcosis (WHO-IWGE): WHO Headquarters, Geneva, Switzerland, 15 - 16 December 2016

Zhang, L., Eslami, A., HosseinI, S., McManus, D. (1998): Indication of the presence of two distinct strains of Echinococcus granulosus in Iran by mitochondrial DNA markers. Am. J. Trop. Med. Hyg., 59(1): 171 - 174. DOI: 10.4269/ajtmh.1998.59.171 